\title{
RESPONSABILIDADE SOCIAL EMPRESARIAL NA HOTELARIA: A VISÃO DE EMPRESAS DE DIFERENTES PORTES E ENTRE DISTINTOS NÍVEIS HIERÁRQUICOS
}

\author{
Ana Carolina Ferreira de Siqueira - UnB ${ }^{1}$ \\ Helena Araújo Costa - UnB ${ }^{2}$
}

Alissandra Nazareth de Carvalho - UFSCar ${ }^{3}$

\begin{abstract}
Resumo: Há uma preocupação global no mundo empresarial em adotar práticas de acordo com o desenvolvimento sustentável. Isso é feito por meio de ações de responsabilidade social empresarial (RSE). Nessa linha, o presente estudo teve como objetivo investigar se a visão de atores organizacionais é influenciada pela variável porte e pelo nível organizacional. O lócus de pesquisa escolhido foram hotéis de Brasília, devido à importância que o turismo ganhou ultimamente no país e a carência de pesquisas que relacionem este setor à responsabilidade social empresarial. A metodologia desenhada foi composta por duas etapas: uma primeira quantitativa, em que um survey foi aplicado junto aos gerentes dos hotéis e uma segunda, com caráter qualitativo, em que foram selecionados dois hotéis e entrevistados representantes do nível gerencial e operacional. Como resultado, verificou-se que as ações de responsabilidade ambiental são mais praticadas pelos hotéis do que as ações sociais e os hotéis de grande porte praticam ações de RSE mais do que os de pequeno porte. As variáveis porte e nível hierárquico foram determinantes para diferenças e semelhanças na visão dos entrevistados.
\end{abstract}

Palavras-chave: Responsabilidade Social Empresarial; Setor Hoteleiro; Diferenças de Porte; Hierarquia Hoteleira.

\section{SOCIAL CORPORATE RESPONSIBILITY IN HOTEL INDUSTRY: A VISION OF COMPANIES OF DIFFERENT SIZES AND BETWEEN DIFFERENT HIERARCHICAL LEVELS}

\begin{abstract}
There is a global concern in corporate to adopt practices in line with sustainable development. This is done by actions of CSR (corporate social responsibility). In this line, the present study aimed to investigate if the view of the organization actors is influenced by variables such as the firm size and the hierarchy levels. The focus of the study is given to the hospitality sector of Brasilia, because of the importance that tourism has now in Brazil, and also because of the lack of researches that relates this sector to CSR. The methodology designed for this purpose was composed of two stages: a first quantitative, in which a survey was applied to the managers of hotels, and a second qualitative, in which two hotels

1E.mail: carolfsiqueira@yahoo.com.br Endereço: Universidade de Brasília- UnB - Campus Universitário Darcy Ribeiro - ICC Ala Norte, Bloco B - $1^{\circ}$ Andar, Sala 576. Brasília - DF

2 E.mail: helenacosta@unb.br

3 E.mail: alissandra@ufscar.br
\end{abstract}

SIQUEIRA, A. C. F; COSTA, H. A; CARVALHO, A. N. Responsabilidade social empresarial na hotelaria: a visão de empresas de diferentes portes e entre distintos níveis hierárquicos. Revista de Empreendedorismo e Gestão de Pequenas Empresas, v. 2, n.2, p.92-115, 2013. 
were selected and representatives of the managerial and operational level were interviewed. As a result, it was found that the actions of environmental responsibility are more practiced by hotels than social actions. And the large hotels practice CSR more than the small ones. It was concluded that the firm size and the hierarchy levels were fundamental to differences and similarities in the practices of corporate responsibility among the hotels in Brasilia.

Keywords: Social Corporate Responsibility; Hotel Sector; Differences of Size; Hierarchy Hospitality.

\section{Introdução}

A atualidade se caracteriza por mudanças no sistema empresarial e pela revisão de conceitos sociais ao redor do globo. Uma dessas revisões é exemplificada pela maior preocupação das organizações com as consequências negativas de suas atividades, além da preocupação com a ética e a moral.

É nesse contexto que estratégias e discursos de responsabilidade social empresarial se tornam comuns. Nota-se que a sua prática não é só um diferencial competitivo, mas pode ser a ideia que permita que a economia global se perpetue com suas adaptações necessárias (ASHLEY, 2005).

Apesar de a responsabilidade estar presente no discurso de muitas empresas e vir se constituindo como uma boa prática empresarial (ASHLEY, 2005), há também ceticismo e divergências sobre o assunto. O tema carece de um tratamento mais crítico (MORETTI; CAMPANARIO, 2009).

Devido ao ceticismo, torna-se importante analisar o discurso sobre RSE (Responsabilidade Empresarial Social) e as visões de diferentes grupos sociais sobre um mesmo tema. Nesse sentido, é imprescindível investigar que variáveis alteram a visão sobre RSE no contexto empresarial. Baseado no artigo de Carrieri, da Silva e Pimentel (2009), tem-se uma indicação de que o nível hierárquico dos respondentes altera a visão que eles têm de RSE.

Nessa linha, o presente trabalho pretende investigar se isso se aplica ao setor hoteleiro de Brasília. Foi escolhido esse lócus de pesquisa devido à importância que o turismo ganhou ultimamente no país graças ao seu crescimento e eventos como Copa do Mundo, Olimpíadas e Rio+20.

Ademais, essa pesquisa busca investigar se o fato de a organização ser

SIQUEIRA, A. C. F; COSTA, H. A; CARVALHO, A. N. Responsabilidade social empresarial na hotelaria: a visão de empresas de diferentes portes e entre distintos níveis hierárquicos. Revista de Empreendedorismo e Gestão de Pequenas Empresas, v. 2, n.2, p.92-115, 
grande ou pequena, o que altera o tamanho de sua estrutura e a distância entre níveis hierárquicos, também altera a visão.

Alguns estudos podem ser citados no campo de interação entre RSE e pequenas empresas, como é o caso dos hotéis de pequeno porte que são, em sua maioria, bastante recentes e apresentam em comum a característica de usar uma abordagem quantitativa, por meio de questionários. A pesquisa atual expõe seu caráter inovador ao analisar a interação entre porte de empresas, níveis hierárquicos e o seu discurso acerca da sua responsabilidade social, usando para tanto uma abordagem qualitativa.

Dessa forma, surgem algumas indagações. Indivíduos de níveis hierárquicos diferentes enxergam as práticas de RSE de uma mesma organização de forma distinta? Empresas de portes diferentes veem e praticam de forma distinta a RSE? Em outras palavras, porte da empresa e nível hierárquico são variáveis que influenciam a visão sobre a RSE nas empresas hoteleiras? Essas são as questões para as quais o presente estudo pretende gerar uma contribuição acadêmica.

\section{Desenvolvimento Sustentável}

O conceito de desenvolvimento sustentável surge com o intuito de diminuir as desigualdades e promover um crescimento que se perpetue pelas próximas gerações (ARAÚJO; MENDONÇA, 2007).

Porém, antes de conceituar "desenvolvimento sustentável", faz-se necessário definir cada um dos termos desse binômio. Em relação a "desenvolvimento" a corrente de estudos mais atual não o enxerga como um simples sinônimo de crescimento econômico nem como algo inalcançável. E sim como um caminho possível, caracterizado por todo um sistema que inclui saúde, educação, segurança, justiça social e liberdade em um contexto amplo.

Em relação ao "sustentável" ou "sustentabilidade", a corrente de estudo mais alinhada a esse artigo acredita que seja possível crescer economicamente e preservar o meio ambiente, mas não nos moldes da economia atual (VEIGA, 2005). 
Nesse sentido, a sustentabilidade seria a busca por um desenvolvimento harmonioso em termos econômicos, sociais e ambientais, de forma a levar em conta a redução da pobreza e das desigualdades sociais e, ao mesmo tempo, a preocupação com as gerações futuras (SACHS, 2004).

Conceituados os termos "desenvolvimento" e "sustentável", pode-se partir para uma revisão do binômio formado por eles. A definição atual de desenvolvimento sustentável apareceu de modo inédito no Relatório "Nosso Futuro Comum", também chamado de Relatório Brundtland em 1987. Segundo esse relatório, "o desenvolvimento sustentável é o que atende às necessidades presentes sem comprometer a capacidade das gerações futuras atenderem também as suas necessidades" (RELATÓRIO BRUNDTLAND, 1987).

Desde o ano de formulação do conceito de desenvolvimento sustentável, o setor privado passou a ser influenciado por ele, já que as empresas são instituições muito importantes no modelo econômico atual, vendo também que isso poderia ser vantajoso para elas. Mesmo assim, boa parte dos avanços feitos nesse sentido não seria possível sem a participação do Estado ou das convenções globais para tratar sobre o assunto.

O desenvolvimento sustentável, como já foi dito, pressupõe a integração de fatores sociais, econômicos e ambientais, mais especificamente, eficiência econômica, justiça social e prudência ecológica, o que ficou conhecido como triple bottom line. É preciso que haja equilíbrio entre as questões do triple bottom line para que uma empresa se mantenha a frente da concorrência e remunere os seus acionistas satisfatoriamente, que são os objetivos principais intrínsecos a qualquer organização privada (OLIVEIRA, 2004).

$\mathrm{Na}$ busca de se adequar à nova ordem global que inclui o desenvolvimento sustentável como um dos valores principais, as empresas desenvolvem práticas que se alinhem a uma responsabilidade econômica em relação aos seus stakeholders. Isto é, ambiental em relação às consequências de algumas de suas atividades e social em relação aos impactos causados nas comunidades com as quais se relaciona. 


\section{Responsabilidade Social Empresarial}

Desde a época de Marx são feitas críticas à importância que as organizações ganharam nas sociedades industriais ocidentais, como elas gerem isso e como se relacionam com seus stakeholders, que são todos os atores que afetam ou são afetados por uma empresa, como clientes, fornecedores, funcionários, acionistas, governo, comunidade, sociedade e outros. Essas críticas evoluíram e resultaram em estratégias e ações das empresas, como forma de rebatê-las, o que ficou conhecido como RSE.

O termo RSE já teve várias definições desde então e muitas existiam, e existem, em paralelo. "A existência de tantas definições de RSE mostra como há uma mistura de ideias, conceitos e práticas em construção que tem provocado acaloradas discussões." (ASHLEY, 2005, p. 13). Bowen (1953) foi um dos primeiros autores a conceituar o termo, ele define responsabilidade social, como "as obrigações dos homens de negócios de adotar orientações, tomar decisões e seguir linhas de ação que sejam compatíveis com os fins e valores de uma sociedade" (BOWEN, 1953, p. 14).

Apesar de ser antigo, o conceito ainda é bastante atual, uma vez que trata RSE de uma forma bem abrangente e faz uma clara referência à estratégia ao afirmar que as orientações, decisões e ações, que são conceitos estratégicos, devem ser feitas alinhadas à perspectiva social. Por outro lado, é possível notar a época em que o conceito foi escrito, ao atentar-se para o fato de ele se referir aos valores de uma única sociedade, no caso, a dos Estados Unidos, pois a preocupação com a globalização ainda não era tão intensa.

Um conceito similar a esse, no que tange a sua amplitude e a interação com stakeholdrers, porém bem mais recente, foi apresentado por Antônio Argandoña e Heidi von Weltzien Hoivik: 
A partir do ponto de vista da empresa, RSE é o conjunto de deveres morais para com outros atores sociais e para com a sociedade que a empresa assume como um resultado de suas reflexões econômicas, sociais, políticas e, é claro, éticas sobre seu papel na sociedade e nas suas relações com esses outros atores. E no que diz respeito a atores externos, é o conjunto de deveres morais que a sociedade e outros agentes atribuem à empresa como uma consequência do papel que esta assume e suas relações com os atores. Na prática, então, a RSE será o resultado de um diálogo entre a empresa e seus stakeholders sobre as obrigações daquela e as expectativas destes." (ARGANDOÑA; HOIVIK, 2009, p. 225).

Argandoña e Hoivik (2009) afirmam que não é possível definir um conceito único, universal ou permanente de RSE, pois há muita diferença entre os países e é importante que o conceito esteja sempre em evolução para se adaptar às necessidades sociais do momento.

Uma importante conceituação é descrita pela ISO 26000 que caracteriza responsabilidade social, entre outras, como algo que "está integrado em toda a organização e praticada em seus relacionamentos com outros atores." (HOIVICK e SHANKAR, 2009, p. 175). Segundo essa conceituação, a RSE deve ser uniforme e estar incorporada em toda a organização. Este tema, o presente trabalho investigou por meio do estudo com hotéis em Brasília.

Carroll (1998) define quatro aspectos que devem ser tratados na responsabilidade social com o intuito de abranger mais ações e torná-las mais efetivas. Os aspectos ou faces são: econômica, legal, ética, e filantrópica. Isto porque, até então, RSE era focada principalmente nas relações com os funcionários e filantrópicas das empresas.

A face econômica é necessária porque antes de ser socialmente responsável, a empresa precisa existir e isso só é possível se ela se mantiver economicamente viável. Bowen (1953, p. 62) também percebe isso ao afirmar que "um negócio que não consegue dar lucro apropriado é um castelo de cartas: não pode aumentar, nem gerar mais empregos ou pagar maiores salários, [...] não pode sequer subexistir".

Sobre a face legal, Carroll (1998) afirma que, se as leis são como códigos de ética nacionais, uma empresa que não as cumpre não pode ser considerada ética ou 
social e ambientalmente responsável. A terceira face de RSE trata da ética nas relações, essa deve ser diferenciada entre descritiva e normativa pelos gerentes de empresas socialmente responsáveis. A ética normativa sempre deve ser levada em conta na tomada de decisões (CARROL,1998).

A última face descrita por Carroll (1998) diz respeito à filantropia. De acordo com o autor, as empresas devem reverter parte do que elas extraem das comunidades como capital, trabalho, recursos naturais e devolvê-los em forma de doações, trabalhos sociais e outras ações que melhorem a qualidade de vida de todos e propiciem um futuro melhor.

\begin{tabular}{|c|c|}
\hline Faces & Descrição \\
\hline Econômica & $\begin{array}{c}\text { A necessidade de uma } \\
\text { empresa de se manter } \\
\text { economicamente viável } \\
\text { para que possa continuar } \\
\text { existindo e mantendo os } \\
\text { empregos que criou. }\end{array}$ \\
\hline \multirow{5}{*}{ Legal } & $\begin{array}{c}\text { Leis são como um código } \\
\text { de ética nacional. Uma } \\
\text { empresa que infringe leis } \\
\text { não pode ser ética. }\end{array}$ \\
\hline Ética & $\begin{array}{c}\text { A ética normativa, } \\
\text { baseada em princípios } \\
\text { racionais deve ser usada } \\
\text { em detrimento da ética } \\
\text { descritiva, baseada } \\
\text { apenas no que acontece. }\end{array}$ \\
\hline Filantrópica & $\begin{array}{c}\text { Devolver para a } \\
\text { sociedade por meio de } \\
\text { doações e ações sociais } \\
\text { parte do que se extrai } \\
\text { dela. }\end{array}$ \\
\hline & \\
\hline &
\end{tabular}

Quadro 1: Faces de RSE segundo Carrol

Fonte: Elaborado pelas Autoras

Ainda no contexto internacional, há uma interessante definição feita por um respondente de um questionário aplicado na Irlanda para o artigo de Aaronson, (2003): "[RSE é] fazer a coisa certa mesmo quando ninguém está olhando." (AARONSON, 2003, p. 323).

Ao se trazer o conceito de RSE para o cenário brasileiro, uma definição importante é a descrita por Ashley (2005). O seu conceito revela uma interface com 
o de sustentabilidade, construto que engloba tanto os aspectos locais das ações das empresas quanto os globais e reforça que as ações de RSE ocorrem de forma voluntária e extrapolando o que é exigido em lei.

Outro conceito brasileiro interessante é o do Instituto Ethos. Assim como no conceito anterior, na definição desse instituto há uma clara referência à sustentabilidade na ideia de preocupação com as gerações futuras. Nota-se que é um conceito aplicado ao contexto brasileiro, pois chama atenção para a necessidade de redução das desigualdades sociais e aponta RSE como forte aliada nesse plano.

Conforme pode ser visto na conceituação feita até aqui, parte das referências é relativamente antiga. Moretti e Campanario (2009) indicam que parece haver uma zona de conforto no campo de RSE, em que novos pesquisadores não têm suas publicações citadas, o que inibe o surgimento de novos talentos na área. Uma alternativa para evitar essa repetição, é buscar conceitos internacionais mais recentes e novos autores no exterior, em que o campo de RSE parece estar em franca expansão. Fora isso, é fundamental que a RSE seja estudada junto a outras áreas do conhecimento, como o turismo, por exemplo, o que é o caso desse estudo.

\section{Responsabilidade Social e Porte Empresarial: distinções entre as pequenas e grandes empresas}

As pequenas e micro empresas tratadas nesta pesquisa são assim consideradas de acordo com o critério do SEBRAE, que leva em conta o número de funcionários. Empresas de até 49 funcionários são tidas como micro ou pequenas (SEBRAE, 2011).

Em 2001, tais empresas empregavam $60,8 \%$ dos postos de trabalho do comércio e serviço (BERNARDES, 2006). Esse autor pesquisou 294 micros e pequenas empresas do Distrito Federal, e $82 \%$ delas se mostraram socialmente responsável de acordo com os seus critérios. Outro estudo sobre micro e pequenas empresas, publicado em maio de 2012 pelo SEBRAE sobre suas práticas de sustentabilidade, mostrou que a maior parte delas, 54\%, não vê a sustentabilidade como oportunidade de ganhos. Apesar disso, grande parte dos empresários pratica

SIQUEIRA, A. C. F; COSTA, H. A; CARVALHO, A. N. Responsabilidade social empresarial na hotelaria: a visão de empresas de diferentes portes e entre distintos níveis hierárquicos. Revista de Empreendedorismo e Gestão de Pequenas Empresas, v. 2, n.2, p.92-115, 
alguma forma de sustentabilidade em seus aspectos ambientais

Há diversas teorias que tentam explicar a relação entre MPEs e RSE. A que mais se aplica a esse trabalho é intitulada de "abordagem verde". Um dos maiores expoentes dessa abordagem é Schumacher que cunhou o slogan "small is beautiful". Segundo o autor (SCHUMACHER, 1974 apud GOSS, 1991), apenas as pequenas empresas poderiam não agredir muito o meio ambiente, gerar relações de trabalho mais justas e aproveitar genuinamente as capacidades humanas.

Um estudo feito em 2009 por Hoivick e Shankar aponta que muitas empresas médias ou pequenas não praticam RSE por não sentirem essa demanda do mercado e por considerarem os custos de implementação muito altos. Tais autores também apresentam vantagens, desvantagens e motivações que as micros e pequenas empresas têm na prática de RSE se comparadas às grandes. Entre as vantagens estão a pouca pressão por resultados que sofrem dos acionistas e processo de tomada de decisão simples. Entre as desvantagens estão: falta de pessoal e falta de instrumentos de gestão voltados para RSE em micro e pequenas empresas.

No que tange a prática de RSE nas grandes empresas, nota-se que elas sofrem maior pressão da comunidade e da mídia do que as pequenas empresas, talvez por isso, as suas ações de RSE sejam mais divulgadas. Apesar de ter mais ações, as grandes empresas, principalmente as matrizes que apresentam filiais em outra cidade ou as multinacionais, enfrentam dificuldade para adaptar suas práticas à realidade local e, por isso, tendem as ser pouco efetivas (ALIGRELI, 2000; VINHA, 1999)

\section{Responsabilidade Social Empresarial: a atuação dos diferentes níveis hierárquicos}

Desde sua concepção, a responsabilidade social empresarial é muito marcada pela atuação da cúpula estratégica. Iniciativas de projetos de cunho social ou ambiental tendem a partir dos dirigentes, mas têm muito apoio dos outros empregados (PELIANO, 2001). As empresas procuram envolver os empregados de 
alguma forma com as práticas de RSE, uma vez que isso aumenta a motivação deles em relação à organização e traz outras vantagens como maior identificação dos funcionários com a missão da empresa (HOIVICK; SHANKAR, 2009; PELIANO, 2001).

O estudo feito por Carrieri, da Silva e Pimentel (2009) mostra uma visão diferente, em que a participação dos diferentes níveis hierárquicos não é uniforme. São expostas contradições e fragmentações de discurso entre os níveis técnico e gerencial sobre o tema ambiental inserido no discurso de RSE. O nível gerencial apresenta-se bastante alinhado à cúpula estratégica, ou seja, apoia a forma como as ações de RSE se dão na empresa. Já o nível técnico critica a sua pouca participação nas decisões de RSE e a pouca participação do nível gerencial nas atividades práticas sobre o tema.

\section{Responsabilidade Social Empresarial no Turismo e na Hotelaria}

No contexto brasileiro, os serviços turísticos, mais especificamente os de hotelaria, começaram a ser prestados no país em 1916 no Rio de Janeiro por um único hotel. Nos anos 70, chegaram grandes redes internacionais como a Othon e Luxor. Nos anos 80 surgiram os apart hotéis. Atualmente, a hotelaria no país está em franca expansão devido ao potencial turístico do Brasil (CASTRO, 2009), e foi incrementada pelos eventos internacionais que terão sede no país, como a Copa em 2014 e as Olimpíadas em 2016.

Nota-se uma movimentação mundial do setor hoteleiro no sentido de tornar suas práticas mais ambientalmente responsáveis. Isso ocorre devido a pressões de vários setores da sociedade como as ONGs (CARVALHO; ALBERTON, 2008; CASTRO, 2009). Isto é necessário porque o turismo pode causar grandes impactos positivos ou negativos (MEDAGLIA, 2010).

Um dos poucos estudos empíricos sobre a interação de RSE e turismo foi feito por Medaglia (2010) e mostra que das 1.335 empresas parceiras do Instituto Ethos, apenas 48 tinham alguma relação com o turismo. Não foi encontrada 
nenhuma grande empresa do setor, como alguma grande rede hoteleira parceira do instituto.

Castro (2009) estudou a gestão ambiental dos hotéis de Brasília, localidade foco deste estudo. Ela relevou atraso dos estabelecimentos da cidade nesse campo. "Pode-se considerar que os hotéis [...] em Brasília, Distrito Federal, não aplicam a maioria das orientações da gestão ambiental" (CASTRO, 2009, p. 88). Talvez isso ocorra devido a dificuldades de falta de cultura organizacional sobre o tema e de recursos financeiros enfrentados pelos hotéis (VIEIRA; HOFFMANN, 2006).

Uma pesquisa sobre hotéis da Estrada Real, realizada por Carvalho e Alberton em 2008, identificou que 57\% das empresas pesquisadas não praticam responsabilidade social. $61 \%$ praticam RSE em seus aspectos sociais e $54,71 \%$ a praticam em seus aspectos ambientais.

\section{Metodologia}

A metodologia da pesquisa se caracteriza por um aspecto exploratório e descritivo com um viés analítico que ocorreu em duas etapas: a primeira quantitativa e a segunda qualitativa. Apesar desta divisão, as partes qualitativa e quantitativa são analisadas em conjunto. Isso é necessário, uma vez que "não há quantificação sem qualificação" e que "não há análise estatística sem interpretação" (BAUER; GASKEEL, 2010, p. 24).

O setor objeto de estudo, hotéis do setor hoteleiro sul e norte de Brasília, teve seus primeiros empreendimentos no ano de fundação da cidade, isto é, em 1960. Brasília apresenta alguns pontos turísticos, assim como a região a sua volta (ALMEIDA, 2008). Este setor conta com 29 hotéis. 14 destes eram pequenos e o restante (15) grandes. Destes, 18 hotéis responderam a primeira etapa do estudo, aproximadamente $62 \%$ do total. O número de hotéis considerados como respondente (18) é diferente do número de questionários preenchidos. Isso porque um dos respondentes preencheu representando uma rede, que incluía ele e mais dois hotéis.

Todas as análises foram feitas com base em 16 respostas. Destes, 8 eram 
de grande porte e a outra metade de pequeno porte. Os funcionários que responderam os questionários eram do nível gerencial e 69\% deles trabalhavam há mais de 5 anos no hotel.

O instrumento da etapa quantitativa do estudo (o questionário) foi baseada nos formulários de investigação de RSE de Carrieri, da Silva e Pimentel (2009), Carvalho e Alberton (2008), Castro (2009) e Font (2011). Para a coleta de dados foram usados questionários impressos transcritos para o Googledocs. A análise desses dados foi feita com a ajuda do SPSS em que foi feita a análise de medidas de associação.

Nessa associação, o cruzamento principal de dados se deu entre o porte, uma variável classificada como ordinal e as outras variáveis que eram também ordinais ou nominais. Por esse motivo, para analisar se havia relação foi usada a significância e para analisar o seu grau foi usado o coeficiente de relação " $\mathrm{t}$ " de Kendall, mais adequado do que o de Pearson usado para analisar variáveis intervalares e com razão, o que não era o caso. É também mais adequado que o de Spearman, uma medida paramétrica usada para casos em que há distribuição normal, o que não foi encontrado (MALHOTRA, 2012).

Após a aplicação dos questionários, foram escolhidas duas empresas para um aprofundamento de caráter qualitativo: um hotel grande e um pequeno. Foram convidados dois representantes do nível operacional e dois do nível tático ou estratégico, entendido como gerencial, em cada um dos dois hotéis.

Para essa etapa qualitativa, o roteiro de pesquisa baseou-se no utilizado por Carrieri et al. (2009). As entrevistas foram do tipo semiestruturadas, pois parece ser o mais adequado por estimular a sinceridade do respondente. Após as entrevistas, foi realizada uma transcrição fiel das respostas. Depois, os dados foram organizados e foram criadas categorias de análise de acordo com o proposto por Bauer e Gaskeel (2010) em sua metodologia de análise de conteúdo.

\section{Resultados e Discussão}


A seguir são discutidos os resultados encontrados e que foram divididos em acordo com a abordagem de pesquisa.

\section{Etapa Quantitativa}

A primeira pergunta do questionário era em relação às diretrizes de RSE. De acordo com o número de respostas obtidas, a diretriz mais praticada pelos hotéis é a que diz respeito à integração das ações por todos os níveis hierárquicos da empresa. Essa opção apresentou o grau de significância de 0,009 com a variável do porte, o que caracteriza que há uma relação. A correlação de Kendall foi de 0,674, o que mostra que quanto maior o porte, mais indivíduos escolheram essa opção, conforme pode ser visto no gráfico 1 .

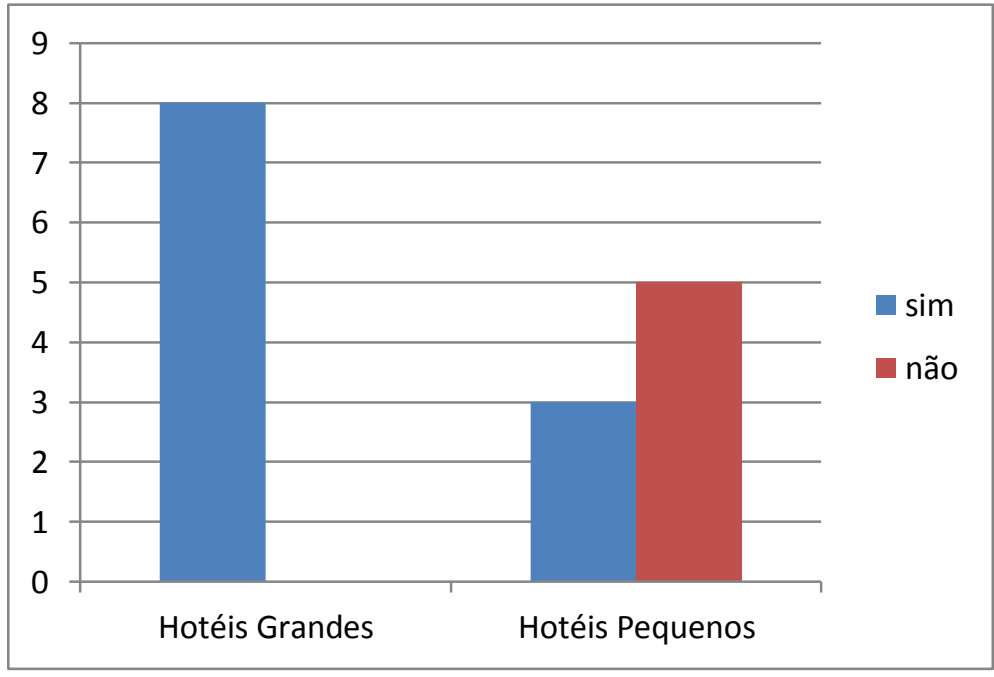

Gráfico 1: Porte e Integração de RSE por toda a Empresa Fonte: Elaborado pelas Autoras

Quanto às atividades de RSE na dimensão social, a mais praticada pelos hotéis é o apoio a atividades desportivas e culturais da cidade. Metade dos hotéis de pequeno porte afirmou não praticar nenhuma atividade descrita. Os grandes hotéis apresentaram mais respostas do que os pequenos no que tange à dimensão social. Em relação à avaliação que os respondentes fazem das atividades de responsabilidade social, as respostas se concentram em "boa", com $63 \%$. Essa 
variável também apresentou relação com o porte sendo que sua significância foi 0,038 e seu coeficiente de Kendall foi de 0,512. Quanto maior a empresa, mais elas estão satisfeitas com as atividades de RSE que praticam. Isso é coerente com o fato de essas empresas praticarem mais ações que as pequenas.

No que tange a atividades de RSE na dimensão ambiental, as mais praticadas pelos hotéis dizem respeito à redução de impactos negativos e de desperdício, cada uma com $75 \%$ do total de respondentes. Assim como na dimensão social, os grandes hotéis marcaram mais respostas que os pequenos.

$\mathrm{Na}$ avaliação das atividades ambientais do hotel a opção "boa" obteve $69 \%$ das respostas. Essa variável também apresentou relação com o porte, sua significância foi 0,010 e seu coeficiente de Kendall foi de 0,640. Esse comportamento é coerente com o fato de os grandes hotéis praticarem mais essas atividades. Outra possível explicação é que eles tenham uma visão mais positiva sobre si mesmos.

As ações ambientais são mais praticadas pelos hotéis do que as sociais. Tal resultado difere do encontrado por Carvalho e Alberton (2008) em um estudo feito nos pequenos hotéis da Estrada Real, MG. Um dos motivos para os resultados encontrados no presente estudo pode estar no fato de as ações sociais requererem mais planejamento e acompanhamento.

O questionário foi dividido em "motivos" (Por quê?) e "vantagens" (consequências). Notam-se algumas inconsistências no que é visto como motivação e vantagem. Por exemplo, os clientes são tidos como motivação por $19 \%$ dos respondentes, mas $50 \%$ deles enxergam o aumento da satisfação dos clientes como vantagem. O gráfico 2 apresenta outras diferenças e semelhanças. No eixo vertical está o número absoluto de respostas: 


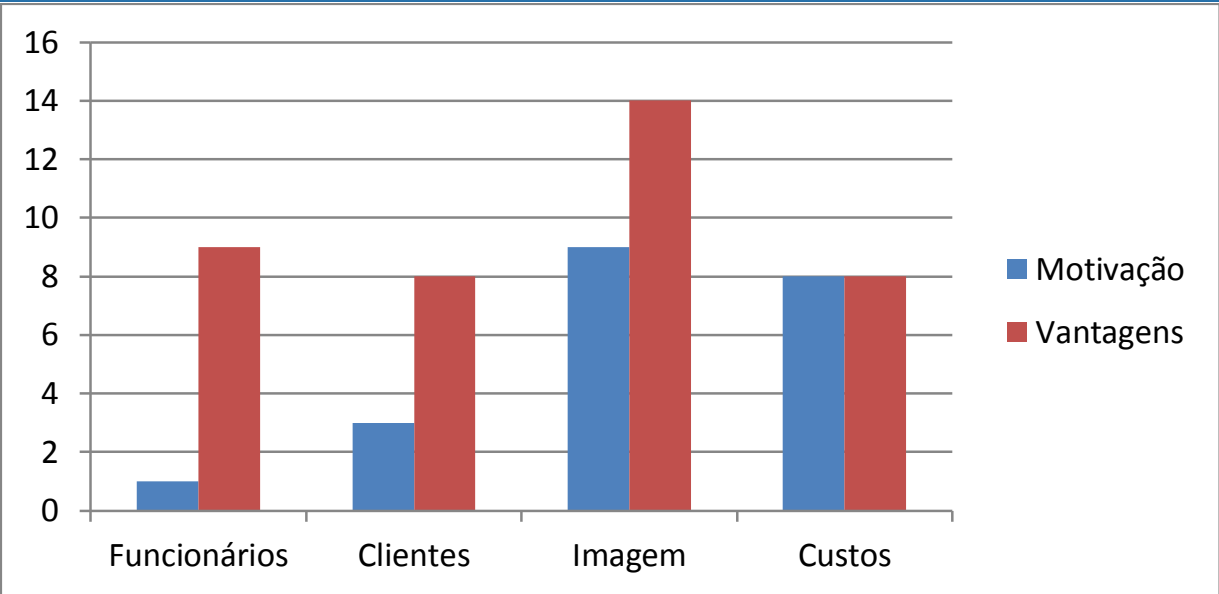

Gráfico 2: Motivações e Vantagens nas Práticas de RSE Fonte: Elaborado pelas Autoras

Em relação ao envolvimento de cada nível hierárquico (operacional, tático e estratégico), a avaliação de todos os níveis apresentou relação positiva com o porte, conforme pode ser visto na Tabela 1: 


\begin{tabular}{|l|c|c|}
\cline { 2 - 3 } \multicolumn{1}{l|}{} & Significância & $\begin{array}{c}\text { Coeficiente Kendall } \\
\text { tau-b }\end{array}$ \\
\hline $\begin{array}{l}\text { Envolvimento do nível } \\
\text { operacional }\end{array}$ & 0,007 & 0,659 \\
\hline Envolvimento do nível tático & 0,007 & 0,659 \\
\hline $\begin{array}{l}\text { Envolvimento do nível } \\
\text { estratégico }\end{array}$ & 0,028 & 0,545 \\
\hline
\end{tabular}

Tabela 1: Kendall tau-b das Variáveis de Envolvimento de Nível Hierárquico

Fonte: Elabora pelas Autoras

Isso, provavelmente, deve-se ao fato de, nas empresas grandes, haver maior clareza dos níveis hierárquicos. Dessa forma, torna-se mais fácil afirmar o envolvimento de cada parte. Entre os hotéis pequenos é sempre maior o número de não envolvidos, em qualquer um dos níveis perguntados. $E$, de forma similar aos resultados encontrados por Carrieri, da Silva e Pimentel (2009), o nível estratégico é o mais envolvido com a implementação das atividades de RSE, apesar das diferenças de envolvimento deste nível para o operacional não ser tão drástica quanto a encontrada por este autor.

Em relação à concordância com as práticas de RSE no hotel, $87,5 \%$ dos respondentes afirmaram que concordam com tais práticas. Houve apenas uma resposta negativa e uma "parcial", mas as duas foram de hotéis pequenos. Isso é coerente com a avaliação, em sua maioria positiva, tanto da responsabilidade social quanto da responsabilidade ambiental feita pelos respondentes.

No que tange à coerência, $50 \%$ dos respondentes avalia que há "muita coerência" entre discurso e prática de RSE na sua empresa. Isso pode ter ocorrido devido à falta de um discurso emitido pela empresa para o público externo, tratado aqui como divulgação. Apenas $25 \%$ dos respondentes afirmam que suas empresas divulgam tais ações. Por esse motivo, suspeita-se que a coerência julgada pelos respondentes consiste em não divulgar e não praticar as ações, e não que de fato as empresas sejam coerentes entre o que fazem e o que dizem fazer. 


\section{Etapa Qualitativa}

$\mathrm{Na}$ segunda etapa, foram analisadas as entrevistas feitas com os oito participantes. Foi perguntado aos entrevistados o que era responsabilidade social

\begin{tabular}{|c|c|c|c|c|}
\cline { 2 - 5 } \multicolumn{1}{c|}{} & \multicolumn{2}{c|}{ Grande Hotel } & \multicolumn{2}{c|}{ Pequeno Hotel } \\
\hline Gerente & $\begin{array}{c}\text { Falou da } \\
\text { sustentabilidade } \\
\text { e da integração } \\
\text { de RS em todos } \\
\text { os níveis }\end{array}$ & $\begin{array}{c}\text { Responsabilidade } \\
\text { em relação ao } \\
\text { ambiente e } \\
\text { educação } \\
\text { ambiental }\end{array}$ & Não sabia & $\begin{array}{c}\text { Falou da } \\
\text { preocupação } \\
\text { com os } \\
\text { funcionários }\end{array}$ \\
\hline & $\begin{array}{c}\text { Falou da } \\
\text { responsabilidade } \\
\text { do seu cargo }\end{array}$ & Não sabia & $\begin{array}{c}\text { Enfatizou } \\
\text { responsabilidade } \\
\text { como um todo, falou } \\
\text { dos funcionários e } \\
\text { de assumir } \\
\text { responsabilidades, } \\
\text { procurar fazer da } \\
\text { forma correta }\end{array}$ & $\begin{array}{c}\text { Falou da } \\
\text { responsabilidade } \\
\text { do seu cargo }\end{array}$ \\
\hline
\end{tabular}

empresarial na opinião deles.

Quadro 2: Resumo da Categoria 1

Fonte: Elaborado pelas Autoras

Mesmo não sabendo o conceito preciso de RSE, todos os respondentes souberam identificar as práticas de seus hotéis nesse âmbito, o que sugere que o termo seja muito mais usado na academia do que no cotidiano das empresas. No hotel grande, pelas práticas serem mais desenvolvidas e formalizadas, as respostas foram mais homogêneas. Foram citadas mais práticas na dimensão ambiental do que na social, o que está de acordo com os resultados do questionário.

Todos os respondentes afirmaram estar envolvidos nas práticas de RSE. Porém, tanto no hotel grande quanto no pequeno, parece haver uma separação entre as atividades dos gerentes e dos funcionários do nível operacional. Seguindo a divisão clássica de tarefas em uma organização, conforme apresentado por Chiavenato (2004), o nível gerencial, tanto tático quanto estratégico, é responsável 
por pensar ações e depois supervisionar a execução, que é feita pelo pessoal do nível operacional. O Quadro 2 dá alguns exemplos de atividades de cada nível hierárquico:

\begin{tabular}{|l|l|l|}
\cline { 2 - 3 } \multicolumn{1}{l|}{} & Gerência & Operacional \\
\hline Atividade principal: & $\begin{array}{l}\text { Pensar ações e } \\
\text { supervisioná-las }\end{array}$ & $\begin{array}{l}\text { Executar ações e reportar } \\
\text { erros }\end{array}$ \\
\hline & $\begin{array}{l}\text { Separar lixo para } \\
\text { reciclagem, reportar } \\
\text { problemas no sensor de } \\
\text { presença, torneiras } \\
\text { vazando. }\end{array}$ \\
\hline
\end{tabular}

Quadro 2: Envolvimento do Respondente com Práticas de RSE

Fonte: Elaborado pelas Autoras

Quanto ao envolvimento do nível operacional com as atividades de RSE, todos os entrevistados afirmaram que há envolvimento pelo menos de parte desse nível hierárquico. Afirmaram também que há abertura para eles fazerem sugestões de melhoria nas ações de RSE.

O fato de o nível operacional estar envolvido está de acordo com o encontrado nos questionários, já que nesse instrumento apenas $25 \%$ afirmaram não haver envolvimento desse nível com a implementação de atividade de RSE. No entanto, o nível de envolvimento não apresentou relação com o porte, o que difere do encontrado no questionário.

Em relação ao envolvimento do nível gerencial, todos os entrevistados no pequeno hotel afirmam haver envolvimento. No grande hotel, um entrevistado diz que esse envolvimento precisa melhorar. Como na questão anterior, o resultado de haver grande envolvimento do nível gerencial está de acordo com o encontrado no questionário, mas o fato de no grande hotel haver mais envolvimento do que no pequeno causa surpresa.

No que tange a avaliação das práticas de RSE, não há uma percepção muito crítica no pequeno hotel em relação à RSE se comparado ao grande hotel. Há uma avaliação mais positiva no pequeno hotel do que no grande, talvez isso ocorra devido à ações serem menos praticadas nele. Isso vai de encontro aos resultados 
da etapa quantitativa do estudo.

Em relação às melhores e piores práticas de RSE, também entendidos como aspectos que estão bons e que precisam melhorar, o quadro 3 resume as respostas que foram encontradas.

\begin{tabular}{|c|c|c|}
\hline & Hotel pequeno & Hotel grande \\
\hline $\begin{array}{l}\text { Aspectos que } \\
\text { estão bons }\end{array}$ & Economia de energia & $\begin{array}{l}\text { Alto investimento em RSE, troca de } \\
\text { equipamentos, uso de } \\
\text { biodegradáveis, economia de energia, } \\
\text { separação do lixo para reciclagem, } \\
\text { reconhecimento e conscientização } \\
\text { das ações de RSE, preocupação } \\
\text { social do hotel, doação de materiais } \\
\text { usados. }\end{array}$ \\
\hline $\begin{array}{l}\text { Aspectos que } \\
\text { precisam melhorar }\end{array}$ & $\begin{array}{l}\text { Ações sociais, } \\
\text { reciclagem e rigidez na } \\
\text { cobrança. }\end{array}$ & $\begin{array}{l}\text { Fazer parcerias com os fornecedores } \\
\text { socialmente responsáveis, divulgar } \\
\text { mais as ações, o fato de alguns } \\
\text { funcionários não agirem se forma } \\
\text { socialmente responsável, o fato de os } \\
\text { materiais, às vezes, não serem } \\
\text { jogados no lixo adequado. }\end{array}$ \\
\hline
\end{tabular}

Quadro 3: Melhores e Piores Aspectos de RSE Praticados na Empresa Fonte: Elaborado pelas Autoras

Quanto aos objetivos, no hotel pequeno cada entrevistado identificou um como o principal. No hotel grande, houve mais homogeneidade, os principais objetivos identificados foram o compromisso com a sociedade e a atração de clientes.

O objetivo de redução de custos, que obteve mais respostas no questionário, não foi citado no hotel grande, um deles ainda disse que "ser sustentável é muito caro" (Entrevistado 5). Um dos entrevistados vê como maior motivação "evitar multas" (Entrevistado 8), o que vai de encontro ao proposto por Ashley (2005).

Em relação ao que os clientes pensam do hotel e de sua RSE, todos os 
respondentes estão alinhados e cientes sobre seus pontos fortes e fracos. No que tange às opiniões dos hóspedes do pequeno hotel, nota-se que as poucas ações de RSE que ele faz não são percebidas pelos clientes. Mais do que isso, um dos entrevistados afirmou que poucos clientes se importam com ações de RSE, conforme pode ser visto no relato abaixo:

Para ser sincera, os hóspedes gastam [água] é muito, tem vez que a gente entra nos apartamentos e as torneiras estão abertas, então eles não ligam não pra isso não. É difícil uns para ligar pra isso, eles deixam a torneira aberta, o ar-condicionado ligado, então eles... eles não tão nem aí não. E nunca nenhum me perguntou se a gente economiza água, economia luz, nunca perguntaram não. Até agora, não. (Entrevistado 4).

No grande hotel, todos os entrevistados afirmaram que ele é muito elogiado, principalmente no que tange ao atendimento. Sobre a RSE, não há comentários por parte dos clientes, o que é visto de forma positiva pelos funcionários, uma vez que se não estivesse adequado, eles reclamariam. A pouca valorização que os clientes atribuem à RSE, na opinião dos entrevistados, pode ser uma característica dos hóspedes de Brasília que, em sua maioria, vêm à cidade a negócios e, muitas vezes, são suas empresas que escolhem seus hotéis.

Por fim, vale dizer que se a pesquisa tivesse ocorrido em uma cidade turística em que há maior interação com a natureza, talvez os resultados fossem bem diferentes.

\section{Considerações Finais}

O presente trabalho teve como objetivo investigar as diferenças na visão sobre a RSE em hotéis de diferentes portes e entre distintos níveis hierárquicos. Verificou-se que os hotéis de grande porte praticam ações de RSE mais do que os de pequeno porte e dentre essas, as ações de responsabilidade ambiental são mais praticadas do que as ações sociais. Pelo alcance dos objetivos propostos, o estudo serve como introdução para as práticas de responsabilidade social dos hotéis de Brasília e as diferenças entre porte e nível hierárquico, algo que ainda não havia 
sido pesquisado com essas especificações.

A metodologia desenhada para o alcance dos objetivos propostos foi composta por duas etapas: uma primeira quantitativa, em que um survey foi aplicado junto aos gerentes dos hotéis, e uma segunda com caráter qualitativo, em que foram selecionados dois hotéis e entrevistados representantes do nível gerencial e operacional.

Pelos questionários e entrevistas, foi possível verificar que alguns aspectos de RSE são vistos de forma semelhante em hotéis de grande e pequeno porte. Já outros são vistos de forma diferente. Entre aqueles vistos de forma similar estão o fato de os dois hotéis saberem seu ponto forte na visão dos clientes e existir uma separação entre as atividades do nível gerencial e operacional. Como diferenças, encontram-se: os objetivos e motivações das ações de RSE e também a criticidade em relação ao tema, que se mostrou bem maior no hotel grande.

Em relação à investigação que teve como variável o nível hierárquico, algumas semelhanças são: os dois níveis enxergam uma separação de tarefas (em que as pessoas do nível operacional são responsáveis pela execução e gerentes pela supervisão), e também que há abertura para o nível operacional sugerir ações ou mudanças. No que tange às diferenças, as pessoas de níveis operacionais avaliam mais positivamente as ações de RSE do que os gerentes.

Contudo, houve algumas limitações, o que é inerente a qualquer pesquisa. A primeira limitação foi o pequeno número de respondente dos questionários. Dos 29 hotéis grandes e pequenos, apenas 18 deles responderam o questionário, apesar de todos terem sido contatados. A segunda limitação é que não é possível generalizar os dados das entrevistas para toda a amostra, pois apenas dois empreendimentos podem ser insuficientes para compreender detalhes. A última limitação encontrada foi o uso da análise de conteúdo para compreensão das respostas das entrevistas, enquanto o mais adequado provavelmente seria a análise de discurso.

Por essas e outras razões, recomenda-se que sejam feitos mais estudos sobre o tema, com o intuito de aprofundá-lo. Uma das sugestões é que seja usada a análise de discurso para compreender as diferenças de discurso sobre RSE, também uma metodologia de observação para que as práticas sejam mais bem 
averiguadas. Por último, um escopo que leve em consideração a perspectiva do cliente e uma análise que investigue diferentes tipos de consumidor para descobrir se valorizam a RSE e a sustentabilidade ou se isso é restrito aos hóspedes.

Por fim, conclui-se que há certa distância entre a academia e as empresas no que tange a RSE, uma vez que poucos entrevistados sequer sabiam o significado do termo, que já é tratado por pesquisadores há décadas. Pesquisas como essa diminuem a distância e levam conceitos e ideias para as empresa conforme foi notado por um entrevistado.

Em relação aos clientes, ficou claro que eles não valorizam práticas de RSE o suficiente para motivarem as empresas a adotá-las. Isso, novamente reforça a importância da academia para cobrar tais ações e, principalmente, de órgãos do governo, dado que, se depender dos clientes, elas podem não ocorrer.

\section{Referências:}

AARONSON, A. S. Corporate responsibility in the global village: The British role model and the American laggard. Business and Society Review, v. 108, n. 3, p. 309-328, 2003.

ALIGRELI, L. M. Responsabilidade social das grandes empresas de Londrina e região. Monografia (Graduação e Administração de Empresas) 2000. - Universidade Estadual de Londrina, 2000.

ALMEIDA, T. R. Mapeamento de competências organizacionais e profissionais de um hotel do distrito federal. Monografia (Especialização em Administração). 2008. 87f. Faculdade de Economia, Administração e Ciências da Informação e Documentação - Universidade de Brasília, 2008.

ARAÚJO, G. C.; MENDONÇA, P. S. M. O Processo de adequação a sustentabilidade empresarial a partir das normas internacionalmente reconhecidas. In: IX ENGEMA - ENCONTRO NACIONAL SOBRE GESTÃO EMPRESARIAL E MEIO AMBIENTE, 9., 2007, Curitiba.

ARGANDOÑA, A.; HOIVIK, H. W. Corporate social responsibility: one size does not fit all: collecting evidence from Europe. Journal of Business Ethics. v. 89, p. 221234, 2009.

ASHLEY, A. P. Ética e responsabilidade social nos negócios. 1. ed. São Paulo: Saraiva, 2005.

SIQUEIRA, A. C. F; COSTA, H. A; CARVALHO, A. N. Responsabilidade social empresarial na hotelaria: a visão de empresas de diferentes portes e entre distintos níveis hierárquicos. Revista de Empreendedorismo e Gestão de Pequenas Empresas, v. 2, n.2, p.92-115, 2013. 
BAUER, M.; GASKELL, G. Pesquisa qualitativa com texto, imagem e som: um manual prático. 8. ed. Petrópolis: Vozes, 2010.

BERNARDES, B. Q. T. Responsabilidade socioambiental das micro e pequenas empresas do DF. Dissertação (Mestrado em Desenvolvimento Sustentável). 2006, 90f. Centro de Desenvolvimento Sustentável - Universidade de Brasília, 2006.

BOWEN, H. Responsabilidades sociais do homem de negócios. Rio de Janeiro: Civilização Brasileira, 1953.

CARRIERI, A. P.; DA SILVA, A. R. L.; PIMENTEL, T. D. O tema da proteção ambiental incorporado nos discursos da responsabilidade social corporativa. Revista de Administração Contemporânea, v. 13, n. 1, art. 1, p. 1-16, Jan./Mar., 2009. Disponível em: <www.anpad.org.br/rac>. Acesso em: 26 ago. 2011.

CARROLL, A. B. The four faces of corporate citizenship. In: Business and society review, v. 100, art. 101, p. 1-7, 1998.

CARVALHO, A. N.; ALBERTON, A. Um estudo em estabelecimentos de hospedagem na Estrada Real/MG: as variáveis social e ambiental. Revista Hospitalidade, São Paulo, v. n. 1, p. 31-57, jun., 2008.

CASTRO, M. R. M. A gestão ambiental nas empresas de serviços: um estudo das práticas nos hotéis de Brasília/DF. Dissertação (Mestrado em Planejamento e Gestão Ambiental).2009. Programa de Pós-Graduação Stricto Sensu em Planejamento e Gestão Ambiental. Universidade Católica de Brasília, Brasília, 2009.

CHIAVEnATO, I. Gestão de Pessoas. Rio de Janeiro: Campus, 2004.

COMISSÃO MUNDIAL SOBRE O MEIO AMBIENTE E DESENVOLVIMENTO.

Nosso futuro comum: Relatório Brutland. Rio de Janeiro: FGV, 1987.

FONT, X. The business case for sustainability Evidence that tourism businesses in protected areas perform best when they also implement sustainability actions. EUROPARC, Federation, Set., 2011.

GOSS, D. Small Business and Society. 2. ed. Londres: Routledge, 1991.

HØIVIK, H. W.; SHANKAR, D. How Can SMEs in a cluster respond to global demands for corporate responsibility? Journal of Business Ethics, v. 101, p.175195. 2009.

INSTITUTO ETHOS. O que é RSE. Disponível em:

$<$ http://webcache.googleusercontent.com/search?q=cache:06RBVUdydJ4J:www1.et

SIQUEIRA, A. C. F; COSTA, H. A; CARVALHO, A. N. Responsabilidade social empresarial na hotelaria: a visão de empresas de diferentes portes e entre distintos níveis hierárquicos. Revista de Empreendedorismo e Gestão de Pequenas Empresas, v. 2, n.2, p.92-115, 2013. 
hos.org.br/EthosWeb/pt/29/o_que_e_rse/o_que_e_rse.aspx+\&cd=1\&hl=ptBR\&ct=clnk\&gl=br>. Acesso em: 14 set. 2011.

MALHOTRA, N. K. Pesquisa de Marketing: uma orientação aplicada. 6. ed. Porto Alegre: Bookman, 2012.

MEDAGLIA, J. Empresas turísticas e ferramentas de gestão de responsabilidade social empresarial: um estudo sobre as empresas associadas ao Instituto Ethos. Caderno Virtual de Turismo, v. 10, n. 1, p. 36-49, 2010.

MORETTI, S. L. A.; CAMPANARIO, M. A. A produção intelectual brasileira em responsabilidade social empresarial - RSE sob a ótica da bibliometria. RAC. Curitiba, v. 13, Edição Especial, art. 5, p. 68-86, Junho, 2009.

OLIVEIRA FILHO, J. E. Gestão ambiental e sustentabilidade: um novo paradigma eco econômico para as organizações modernas. Domus on line, v. 1, n. 1, jan./jun., 2004.

PELIANO, A. M. T. M. Bondade ou Interesse? Como e por que as empresas atuam na área social. Brasília: IPEA, 2001.

SACHS, I. Desenvolvimento: includente, sustentável, sustentado. Rio de Janeiro: Garamond, 2004.

SEBRAE. 2011. O que pensam as micro e pequenas empresas sobre sustentabilidade. Disponível em: <http://www.sebrae.com.br/estudos-e-pesquisas>. Acesso em 30 mai.2012.

VEIGA, J E. Desenvolvimento sustentável: o desafio do século XXI. 3. ed. Rio de Janeiro: Garamond, 2005.

VIERA, E. V.; HOFFMANN, V. E. Práticas de sustentabilidade ambiental para empreendimentos turísticos hoteleiros: aplicação de um modelo. IV SeminTUR, Caxias do Sul, 7 e 8 de Julho, 2006.

VINHA, V. G. A convenção do desenvolvimento sustentável e as empresas eco comprometidas. Tese (Doutorado em Ciências Humanas). 1999. 291f. Instituto de Ciências Humanas e Sociais - Universidade Federal Rural do Rio de Janeiro, 1999.

Artigo recebido em:18/06/2013. Aprovado em 06/08/2013.

SIQUEIRA, A. C. F; COSTA, H. A; CARVALHO, A. N. Responsabilidade social empresarial na hotelaria: a visão de empresas de diferentes portes e entre distintos níveis hierárquicos. Revista de Empreendedorismo e Gestão de Pequenas Empresas, v. 2, n.2, p.92-115, 